\title{
Uso da terapia fotodinâmica na redução de microrganismos das infecções endodônticas
}

Use of photodynamic therapy in the reduction of microorganisms of endodontic infections

Uso de la terapia fotodinámica en la reducción de microorganismos de las infecciones endodónticas

Bruna Angélica de Souza VIANA 1

Marcos Sérgio ENDO2

Nair Narumi Orita PAVAN ${ }^{2}$

${ }^{1}$ Residência em Endodontia - Universidade Estadual de Maringá (UEM), 87080-000 Maringá - PR, Brasil

${ }^{2}$ Professor(a) Adjunto(a) em Endodontia - Universidade Estadual de Maringá (UEM), 87080-000 Maringá - PR, Brasil

\section{Resumo}

Introdução: A terapia fotodinâmica (TFD) se apresenta como uma técnica complementar ao tratamento endodôntico potencializando a desinfecção dos canais radiculares. Objetivo: O objetivo deste trabalho foi buscar estudos que utilizem a TFD como coadjuvante à terapia endodôntica e expor quais são mais recorrentes e propiciam melhores resultados na descontaminação, sugerindo um protocolo para o tratamento endodôntico. Método: $O$ trabalho fundamentou-se em uma pesquisa realizada por meio de levantamento da literatura, mediante a consulta de artigos científicos nas bases de dados (PubMed, LILACS, e Scielo), e para a inclusão dos mesmos na revisão foram utilizados os critérios: artigos em inglês, originais e relevantes, pesquisas clínicas e laboratoriais, em dentes permanentes humanos e que relatassem o uso da terapia fotodinâmica como um tratamento coadjuvante à desinfecção dos canais. Resultados: Após a busca e exclusão pela leitura de títulos e resumos, teve-se 47 artigos, e após a leitura destes na íntegra, utilizando-se os critérios de exclusão, 14 foram utilizados para a revisão. As variáveis diferem nos estudos, no entanto, alguns parâmetros da TFD persistem nas pesquisas, apresentando bons resultados na redução das infecções endodônticas. O protocolo sugerido nesta revisão foi o uso do corante azul de metileno (15 e $25 \mu \mathrm{g} / \mathrm{ml})$; tempo pré-irradiação de 5 minutos; laser diodo (660 nm) e potência de $100 \mathrm{~mW}$; uso de fibra óptica e tempo de irradiação de 5 minutos. Conclusão: O uso da TFD proporciona uma redução bacteriana significativa associado ao preparo químico-mecânico, mostrando a possibilidade de aplicação deste protocolo que apresentou os melhores resultados.

Descritores: Cavidade Pulpar; Endodontia; Fotoquimioterapia.

\section{Abstract}

Introduction: Photodynamic therapy (PDT) presents as a complementary technique to the endodontic treatment, potentiating the disinfection of the root canals. Objective: The aim of this study was to search for studies that use PDT as an adjunct to endodontic therapy and to explain which are more recurrent and provide better results in decontamination, suggesting a protocol for endodontic treatment. Method: The study was based on a literature review, through the consultation of scientific articles in the databases (PubMed, LILACS, and Scielo), and for inclusion in the review, the following criteria were used: articles in English, original and relevant, clinical and laboratory researches, in human permanent teeth and that reported the use of photodynamic therapy as a treatment adjuvant to the disinfection of the channels. Results: After the search and exclusion by reading titles and abstracts, it had 47 articles, and after reading these in full, using the exclusion criteria, 14 were used for the review. The variables differ in the studies, however, some parameters of PDT persist in the research, presenting good results in the reduction of endodontic infections. The protocol suggested in this review was the use of methylene blue dye (15 and $25 \mu \mathrm{gg} /$ $\mathrm{ml}$ ); pre-irradiation time of 5 minutes; laser diode $(660 \mathrm{~nm})$ and power of $100 \mathrm{~mW}$; use of optical fiber and irradiation time of 5 minutes. Conclusion: The use of PDT provides a significant bacterial reduction associated with the chemical-mechanical preparation, showing the possibility of applying this protocol that presented the best results.

Descriptors: Dental Pulp Cavity; Endodontics; Photochemotherapy.

\section{Resumen}

Introducción: La terapia fotodinámica (TFD) se presenta como una técnica complementaria al tratamiento endodóntico potenciando la desinfección de los canales radiculares. Objetivo: El objetivo de este trabajo fue buscar estudios que utilicen la TFD como coadyuvante a la terapia endodóntica y exponer cuáles son más recurrentes y propician mejores resultados en la descontaminación, sugiriendo un protocolo para el tratamiento endodóntico. Método: El trabajo se fundamentó en una investigación realizada por medio de levantamiento da literatura, mediante la consulta de artículos científicos en las bases de datos (PubMed, LILACS, y Scielo), y para la inclusión de los mismos en la revisión se utilizaron los criterios: artículos en inglés, originales y relevantes, investigaciones clínicas y de laboratorio, en dientes permanentes humanos y que relatasen el uso de la terapia fotodinámica como un tratamiento coadyuvante a la desinfección de los canales. Resultados: Después de la búsqueda y exclusión por la lectura de títulos y resúmenes, se tuvieron 47 artículos, y después de la lectura de éstos en su totalidad, utilizando los criterios de exclusión, 14 fueron utilizados para la revisión. Las variables difieren en los estudios, sin embargo, algunos parámetros de la TFD persisten en las investigaciones, presentando buenos resultados en la reducción de las infecciones endodónticas. El protocolo sugerido en esta revisión fue el uso del colorante azul de metileno (15 y $25 \mu \mathrm{g} / \mathrm{ml})$; tiempo pre-irradiación de 5 minutos; láser diodo $(660 \mathrm{~nm})$ y potencia de $100 \mathrm{~mW}$; el uso de fibra óptica y el tiempo de irradiación de 5 minutos. Conclusión: El uso de la TFD proporciona una reducción bacteriana significativa asociada a la preparación químico-mecánica, mostrando la posibilidad de aplicación de este protocolo que presentó los mejores resultados.

Descriptores: Cavidad Pulpar; Endodoncia; Fotoquimioterapia.

INTRODUÇÃO

A infecção microbiana exerce papel elementar nas lesões periapicais persistentes. Se a desinfecção dos canais radiculares for insuficiente poderá promover a continuidade da patologia periapical e levar ao insucesso do tratamento endodôntico ${ }^{1}$.

$$
\text { A terapia fotodinâmica (TFD), }
$$
amplamente estudada nos últimos anos, demonstra sua eficácia contra micro-organismos presentes nas infecções endodônticas e pode ser uma técnica complementar ao tratamento endodôntico, potencializando a desinfecção dos canais radiculares ${ }^{1,2}$.

Buscando otimizar e aperfeiçoar a eliminação bacteriana, seu protocolo baseia-se na interação entre três componentes: um fotossensibilizador, uma fonte de luz e o oxigênio $^{2}$. Os parâmetros da TFD, que são: 
fotossensibilizador e sua concentração, fonte de luz e seu comprimento de onda, tempo de ativação da luz, e uso ou não de fibra óptica, apresentam-se com suas variáveis distintas nos trabalhos existentes, e ainda não há um protocolo padronizado estabelecido para instituir a terapia na Endodontia, até o momento deste levantamento da literatura.

Em vista disso, o objetivo deste trabalho foi buscar estudos que utilizem a TFD como coadjuvante à terapia endodôntica e expor quais fatores são mais recorrentes e propiciam resultados eficazes na descontaminação do sistema de canais, baseando-se na análise dos estudos desta revisão.

\section{MATERIAL E MÉTODO}

O trabalho fundamentou-se em um levantamento da literatura, sendo que a coleta dos dados foi realizada mediante às bases de dados PubMed, LILACS e Scielo, de artigos científicos publicados entre 2006 e 2016.

Após a busca e exclusão pela leitura de títulos e resumos, teve-se 47 artigos na íntegra, e para a seleção destes trabalhos e inclusão dos mesmos na revisão foram utilizados os seguintes critérios: artigos na língua inglesa, originais e relevantes, pesquisas clínicas e laboratoriais, em dentes permanentes humanos e que relatassem o uso da terapia fotodinâmica como coadjuvante na desinfecção de canais radiculares.

As buscas foram realizadas por meio das palavras-chave: endodontics; photodynamic therapy; photodynamic therapy endodontics; light-activated disinfection root canal; photoactivated disinfection endodontics; photoactivated disinfection, fazendo combinações com os operadores booleanos AND ou OR.

\section{RESULTADOS}

Foram analisados 14 estudos, 11 in vitro, 3 estudos clínicos, sendo 1 randomizado e 2 não randomizados. As amostras (n) usadas nos trabalhos in vitro variaram de 10 a 156 dentes humanos. Os estudos clínicos realizados envolveram 20 dentes de pacientes com necrose pulpar e lesão periapical ${ }^{3}, 20$ dentes de pacientes com necessidade de retratamento ${ }^{1} \mathrm{e}$ 21 dentes de pacientes com necessidade de retratamento ${ }^{4}$. Doze trabalhos utilizaram dentes humanos unirradiculares, dois tiveram em suas pesquisas dentes multirradiculares, e destes dois, um utilizou também dentes unirradiculares, e o outro trabalho não forneceu esta informação. Os principais parâmetros das metodologias e da terapia fotodinâmica dos estudos estão detalhados na Tabela 1.
Tabela 1 - Principais parâmetros da TFD dos estudos científicos selecionados

\begin{tabular}{|c|c|}
\hline \multicolumn{2}{|l|}{ Asnaasharios et al. 2016} \\
\hline $\begin{array}{ll}\text { Metodologia } & \text { (Micro- } \\
\text { organismo/ dentes/ solução } \\
\text { irrigadora) }\end{array}$ & $\begin{array}{l}\text { E. faecalis, } F . \text { nucleatum e P. gingivalis } \\
\text { 20 dentes com necessidade de retratamento } \\
\text { Grupo1: NaOCl } 2,5 \%+\mathrm{TFD} \\
\text { Grupo 2: } \mathrm{NaOCl} 2,5 \%+\text { Laser diodo } \\
\end{array}$ \\
\hline $\begin{array}{l}\text { FS/ concentração/ } \\
\text { tempo de pré-irradiação }\end{array}$ & Azul de Metileno/ o, $5 \mathrm{ml} \mathrm{a} 0,01 \% / 5$ minutos \\
\hline $\begin{array}{l}\text { Fonte de luz/ comprimento de } \\
\text { onda/ potência/ } \\
\text { Uso de fibra óptica }\end{array}$ & Laser diodo/ $810 \mathrm{~nm} / \mathrm{o}, 2 \mathrm{~W} / \mathrm{cm}^{2} / \mathrm{Sim}$ \\
\hline Tempo de irradiação & Grupo1: 40s ; Grupo2: 30s \\
\hline Resultados & $\begin{array}{l}\text { Os resultados da análise de dados mostraram } \\
\text { que os valores de UFC/ml foram } \\
\text { significativamente reduzidos no grupo } \\
\text { submetido ao processo da TFD e no grupo } \\
\text { submetido ao laser diodo. }\end{array}$ \\
\hline Conclusões & $\begin{array}{l}\text { TFD e laser diodo/810 } \mathrm{nm} \text { são métodos eficazes } \\
\text { para a desinfecção do canal radicular. }\end{array}$ \\
\hline \multicolumn{2}{|l|}{ Soares et al. 2016} \\
\hline $\begin{array}{ll}\text { Metodologia } & \text { (Micro- } \\
\text { organismo/ dentes/ } \\
\text { irrigadora) }\end{array}$ & $\begin{array}{l}\text { E. faecalis; } 40 \text { Caninos; } \\
\text { NaOCl } 5,25 \%+\text { EDTA } 17 \%\end{array}$ \\
\hline $\begin{array}{l}\text { FS/ concentração/ } \\
\text { tempo de pré-irradiação }\end{array}$ & Azul de metileno/ 1,6 $\mu \mathrm{M} / \mathrm{ml} / 2,5$ minutos \\
\hline $\begin{array}{l}\text { Fonte de luz/ comprimento de } \\
\text { onda/ potência/ } \\
\text { Uso de fibra óptica }\end{array}$ & Laser diodo/ $660 \mathrm{~nm} / 40 \mathrm{~mW} / \mathrm{Sim}$ \\
\hline Tempo de irradiação & 2,5 minutos \\
\hline Resultados & $\begin{array}{l}\mathrm{O} \text { tratamento endodôntico juntamente com } \\
\text { duas sessões de TFD, melhorou a diminuição da } \\
\text { carga bacteriana, e nenhum micro-organismo } \\
\text { resistente foi relatado. }\end{array}$ \\
\hline Conclusões & $\begin{array}{l}\text { A TFD proporcionou uma redução imediata e } \\
\text { progressiva na carga bacteriana. Representa } \\
\text { uma estratégia potencial para a desinfecção } \\
\text { completa de canais radiculados contaminados } \\
\text { por E. faecalis. }\end{array}$ \\
\hline \multicolumn{2}{|l|}{ Susila et al. 2016} \\
\hline $\begin{array}{ll}\text { Metodologia } & \text { (Micro- } \\
\text { organismo/ dentes/ } & \text { solução } \\
\text { irrigadora) } & \end{array}$ & $\begin{array}{l}\text { S. mutans e E. faecalis } \\
\text { 8o dentes unirradiculados } \\
\text { Grupo 1: NaOCl 3\% + EDTA + TFD } \\
\text { Grupo 2: Solução salina + TFD } \\
\text { Grupo 3: } \\
\text { NaOCl 3\% + EDTA } \\
\text { Grupo 4: Solução salina }\end{array}$ \\
\hline $\begin{array}{l}\text { FS/ concentração/ } \\
\text { tempo de pré-irradiação }\end{array}$ & Azul de metileno/ $25 \mu \mathrm{g} / \mathrm{ml} / 5$ minutos \\
\hline $\begin{array}{l}\text { Fonte de luz/ comprimento de } \\
\text { onda/ potência/ } \\
\text { Uso de fibra óptica }\end{array}$ & Laser diodo/ $665 \mathrm{~nm} / \mathrm{1W} / \mathrm{cm}^{2} / \mathrm{Sim}$ \\
\hline Tempo de irradiação & 30 segundos \\
\hline Resultados & $\begin{array}{l}\text { O grupo } 1 \text { com } E \text {. faecalis teve UFC média } \\
\text { significativamente menor do que todos os outros } \\
\text { grupos }(\mathrm{p}=0,001) \text {. Sob o mesmo protocolo de } \\
\text { desinfecção, S. mutans diferiu de E. faecalis na } \\
\text { medida em que tinha } 1 \text { e } 1 / 2 \text { vezes mais UFC (p } \\
=0,05 \text { ). }\end{array}$ \\
\hline Conclusões & $\begin{array}{l}\text { Um forte efeito adicional da aplicação } \\
\text { combinada de irrigantes antimicrobianos e TFD } \\
\text { foi observado na erradicação de patógenos } \\
\text { endodônticos comuns. }\end{array}$ \\
\hline \multicolumn{2}{|l|}{ De Oliveira et al. 2016} \\
\hline $\begin{array}{ll}\text { Metodologia } & \text { (Micro- } \\
\text { organismo/ dentes/ } & \text { solução } \\
\text { irrigadora) } & \end{array}$ & $\begin{array}{l}\text { E. faecalis, } P \text {. aeruginosa, } S \text {. aureus e C. } \\
\text { albicans } \\
\text { 70 pré-molares inferiores unirradiculados } \\
\text { Grupo1: NaOCl 1\%; } \\
\text { Grupo 2: NaOCl 5,25\%; Grupo 3: soro } \\
\text { fisiológico + TFD; Grupo 4: NaOCl 1\% + TFD; } \\
\text { Grupo 5: NaOCl 5.25\% + TFD; } \\
\text { Grupo 6: controle positivo } \\
\text { Grupo 7: controle negativo }\end{array}$ \\
\hline $\begin{array}{l}\text { FS/ concentração/ } \\
\text { tempo de pré-irradiação }\end{array}$ & Azul de metileno/ $15 \mu \mathrm{g} / \mathrm{mL} / 2$ minutos \\
\hline $\begin{array}{l}\text { Fonte de luz/ comprimento de } \\
\text { onda/ potência/ } \\
\text { Uso de fibra óptica }\end{array}$ & Laser diodo/ $660 \mathrm{~nm} / 100 \mathrm{~mW} / \mathrm{Sim}$ \\
\hline Tempo de irradiação & 1,5 minutos \\
\hline Resultados & $\begin{array}{l}\text { NaOCl } 5,25 \%+\text { TFD resultou no maior número } \\
\text { de espécimes sem crescimento microbiano. } \\
\text { Além disso, NaOCl } 1 \% \text { e NaOCl } 1 \%+\text { TFD } \\
\text { apresentaram efeitos antimicrobianos similares. } \\
\text { Soro fisiológico + TFD não eliminou todos os } \\
\text { micro-organismos. Houve diferenças estatísticas } \\
\text { significativas entre os grupos e os micro- } \\
\text { organismos. }\end{array}$ \\
\hline Conclusões & $\begin{array}{l}\text { A associação de NaOCl } 5,25 \% \text { com TFD foi o } \\
\text { tratamento mais eficaz contra microrganismos } \\
\text { de infecção endodôntica. Este resultado mostra } \\
\text { que a TFD pode ser útil para melhorar a } \\
\text { desinfecção do canal radicular. }\end{array}$ \\
\hline
\end{tabular}


Tabela 1 - Continuação. Principais parâmetros da TFD dos estudos científicos selecionados

\begin{tabular}{|c|c|}
\hline \multicolumn{2}{|l|}{ Juric et al. 2014} \\
\hline $\begin{array}{ll}\text { Metodologia } & \text { (Micro- } \\
\text { organismo/ dentes/ } & \text { solução } \\
\text { irrigadora) } & \\
\end{array}$ & $\begin{array}{l}21 \text { dentes unirradiculados com necessidade de } \\
\text { retratamento } \\
\text { NaOCl } 2,5 \% \text { + EDTA } 17 \% \text { + solução salina + } \\
\text { TFD }\end{array}$ \\
\hline $\begin{array}{l}\text { FS/ concentração/ } \\
\text { tempo de pré-irradiação }\end{array}$ & Cloreto de fenotiazina/ $10 \mathrm{mg} / \mathrm{mL} / 2$ minutos \\
\hline $\begin{array}{l}\text { Fonte de luz/ comprimento de } \\
\text { onda/ potência/ } \\
\text { Uso de fibra óptica }\end{array}$ & Laser diodo/ $660 \mathrm{~nm} / 100 \mathrm{~mW} / \mathrm{Sim}$ \\
\hline Tempo de irradiação & 1 minuto \\
\hline Resultados & $\begin{array}{l}\text { Quatorze espécies de bactérias foram isoladas } \\
\text { inicialmente dos canais radiculados. Embora o } \\
\text { retratamento endodôntico tenha reduzido } \\
\text { significativamente o número de espécies de } \\
\text { bactérias (p <o,oo1), a combinação de } \\
\text { tratamento endodôntico e TFD foi } \\
\text { estatisticamente mais efetiva (p < <o,oo1). }\end{array}$ \\
\hline Conclusões & $\begin{array}{l}\text { A TFD junto à preparação convencional do canal } \\
\text { radicular conduziu à redução significativa do } \\
\text { número de UFCs e à eliminação das restantes } \\
\text { das bacterias, ou mesmo a completa eliminação } \\
\text { de bactérias em alguns casos A combinação da } \\
\text { limpeza químico-mecânica e a TFD foi mais bem } \\
\text { sucedida na eliminação de espécies de bactérias } \\
\text { gram-positivas e gram-negativas, anaeróbios } \\
\text { facultativos e anaeróbios obrigatórios } \\
\text { comparando-se com limpeza químico-mecânica } \\
\text { sozinha. }\end{array}$ \\
\hline \multicolumn{2}{|l|}{ Xhevdet et al. 2014} \\
\hline $\begin{array}{ll}\text { Metodologia } & \text { (Micro- } \\
\text { organismo/ dentes/ } \\
\text { irrigadora) }\end{array}$ & $\begin{array}{l}\text { E. faecalis e C. albicans } \\
156 \text { dentes unirradiculados } \\
\text { NaOCl } 2,5 \%+\text { TFD }\end{array}$ \\
\hline $\begin{array}{l}\text { FS/ concentração/ } \\
\text { tempo de pré-irradiação }\end{array}$ & Cloreto de fenotiazina $10 \mathrm{mg} / \mathrm{mL} / \mathrm{min}$ \\
\hline $\begin{array}{l}\text { Fonte de luz/ comprimento de } \\
\text { onda/ potência/ } \\
\text { Uso de fibra óptica }\end{array}$ & Laser diodo $660 \mathrm{~nm} / 100 \mathrm{~mW} / \mathrm{cm} 2 / \mathrm{Sim}$ \\
\hline Tempo de irradiação & 1,3 e 5 minutos \\
\hline Resultados & $\begin{array}{l}\text { O laser reduziu ainda mais as células restantes. } \\
\text { Até agora, a TFD provou ser uma terapia } \\
\text { coadjuvante eficiente. }\end{array}$ \\
\hline Conclusões & $\begin{array}{l}\text { A TFD mostrou-se um método adequado para } \\
\text { desinfecção dos canais, obtendo resultados } \\
\text { semelhantes a irrigação com NaOCl. }\end{array}$ \\
\hline
\end{tabular}

\begin{tabular}{|c|c|}
\hline Conclusões & $\begin{array}{l}\text { desinfecção dos canais, obtendo resultados } \\
\text { semelhantes a irrigação com } \mathrm{NaOCl} \text {. }\end{array}$ \\
\hline \multicolumn{2}{|l|}{ Da Frota et al. 2014} \\
\hline $\begin{array}{ll}\text { Metodologia } & \text { (Micro- } \\
\text { organismo/ dentes/ solução } \\
\text { irrigadora) }\end{array}$ & $\begin{array}{l}\text { E. faecalis } \\
\text { 80 dentes unirradiculados } \\
\text { NaOCl } 2,5 \%+\text { EDTA } 17 \%+\text { soro fisiológico + } \\
\text { TFD } \\
\text { Grupo Ia: Curcumina + luz durante } 5 \mathrm{~min} ; \\
\text { Grupo Ib: Curcumina + luz durante } 10 \mathrm{~min} ; \\
\text { Grupo IIa: Apenas aplicação de curcumina por } \\
\text { 10 minutos; } \\
\text { Grupo IIb Apenas aplicação de curcumina por } \\
15 \text { min; } \\
\text { Grupo IIIa: solução fisiológica + luz durante } 5 \\
\text { min; } \\
\text { Grupos IIIb: solução + luz durante } 10 \text { min. }\end{array}$ \\
\hline $\begin{array}{l}\text { FS/ concentração/ } \\
\text { tempo de pré-irradiação }\end{array}$ & $\begin{array}{l}\text { Curcumina numa solução a } 10 \% \text { de } \\
\text { sulfóxido de dimetilo/ } 20 \mu \mathrm{M} / 5 \text { minutos }\end{array}$ \\
\hline $\begin{array}{l}\text { Fonte de luz/ comprimento de } \\
\text { onda/ potência/ } \\
\text { Uso de fibra óptica }\end{array}$ & $\mathrm{LED} / 450 \mathrm{~nm} / 100 \mathrm{~mW} / \mathrm{cm}^{2} / \mathrm{Sim}$ \\
\hline Tempo de irradiação & 5,10 e 15 minutos \\
\hline Resultados & $\begin{array}{l}\text { Grupo Ia teve a maior redução microbiana } \\
\text { (41\%). } \\
\text { GIIa (redução de } 30 \%) \text {. } \\
\text { GIIb (24\%). GIIIa (26\%). GIIIb (31\%) }\end{array}$ \\
\hline Conclusões & $\begin{array}{l}\text { A TFD reduziu a viabilidade bacteriana usando } \\
\text { Curcumina como fotossensibilizador e } 5 \text { min de } \\
\text { irradiação LED. Nas condições experimentais } \\
\text { testadas, não eliminou significativamente a } \\
\text { contaminação bacteriana por } E \text {. faecalis. }\end{array}$ \\
\hline \multicolumn{2}{|l|}{ Sabino et al. 2014} \\
\hline $\begin{array}{ll}\text { Metodologia } & \text { (Micro- } \\
\text { organismo/ dentes/ } & \text { solução } \\
\text { irrigadora) } & \end{array}$ & $\begin{array}{l}\text { C. albicans } \\
\text { 10 terceiros molares com canais radiculados } \\
\text { curvos } \\
\text { NaOCl } 2,5 \%+\text { EDTA } 17 \%+\text { solução PBS + TFD }\end{array}$ \\
\hline $\begin{array}{l}\text { FS/ concentração/ } \\
\text { tempo de pré-irradiação }\end{array}$ & Azul de metileno $90 \mu \mathrm{M} / 2$ minutos \\
\hline $\begin{array}{l}\text { Fonte de luz/ comprimento de } \\
\text { onda/ potência/ } \\
\text { Uso de fibra óptica }\end{array}$ & Laser tip/ $660 \mathrm{~nm} / 100 \mathrm{~mW} / \mathrm{Sim}$ \\
\hline Tempo de irradiação & 2 e 6 minutos por canal \\
\hline Resultados & $\begin{array}{l}\text { O uso da TFD parece ser uma abordagem } \\
\text { atrativa. Apesar dos bons resultados, } \\
\text { Algumas variáveis devem ser avaliadas. }\end{array}$ \\
\hline Conclusões & $\begin{array}{l}\text { A TFD usando fibras difusoras pode ser um } \\
\text { meio efetivo de inativar micro-organismos } \\
\text { embutidos no biofilme dentro de canais curvos. }\end{array}$ \\
\hline
\end{tabular}

Tabela 1 - Continuação. Principais parâmetros da TFD dos estudos científicos selecionados

\begin{tabular}{|c|c|}
\hline \multicolumn{2}{|l|}{ Rios et al. 2014} \\
\hline $\begin{array}{ll}\text { Metodologia } & \text { (Micro- } \\
\text { organismo/ dentes/ } & \text { solução } \\
\text { irrigadora) } & \end{array}$ & $\begin{array}{l}\text { E. faecalis } \\
\text { Dentes unirradiculados } \\
\text { NaOCl } 6 \%+\text { EDTA } 17 \%+\text { TFD }\end{array}$ \\
\hline $\begin{array}{l}\text { FS/ concentração/ } \\
\text { tempo de pré-irradiação }\end{array}$ & Azul de toluidina/ o,25 ml/ 30 segundos \\
\hline $\begin{array}{l}\text { Fonte de luz/ comprimento de } \\
\text { onda/ potência/ } \\
\text { Uso de fibra óptica }\end{array}$ & LED/ $628 \mathrm{~nm} /-/ \mathrm{Sim}$ \\
\hline Tempo de irradiação & 30 segundos \\
\hline Resultados & $\begin{array}{l}\text { A taxa de sobrevivência bacteriana dos dentes } \\
\text { tratados com NaOCl e TFD }(0,1 \%) \text { foram } \\
\text { significativamente menor }(\mathrm{P}<0,005) \text { do que } \\
\text { quando tratados somente com } \mathrm{NaOCl}(0,66 \%) \text {. }\end{array}$ \\
\hline Conclusões & $\begin{array}{l}\text { TFD usando azul de toluidina e uma lâmpada } \\
\text { LED tem potencial para ser usado como um } \\
\text { procedimento antimicrobiano adjunto na } \\
\text { terapia endodôntica convencional. }\end{array}$ \\
\hline \multicolumn{2}{|l|}{ Ng et al. 2011} \\
\hline $\begin{array}{ll}\text { Metodologia } & \text { (Micro- } \\
\text { organismo/ dentes/ } & \text { solução } \\
\text { irrigadora) } & \end{array}$ & $\begin{array}{l}52 \text { dentes uni e multirradiculados com necrose } \\
\text { pulpar e lesão periapical recém-extraídos } \\
\text { Grupo 1: NaOCl 6\% + EDTA } 17 \% \\
\text { Grupo 2: NaOCl 6\% + EDTA } 17 \% \text { + TFD }\end{array}$ \\
\hline $\begin{array}{l}\text { FS/ concentração/ } \\
\text { tempo de pré-irradiação }\end{array}$ & Azul de metileno/ $50 \mu \mathrm{g} / \mathrm{ml} / 5$ minutos \\
\hline $\begin{array}{l}\text { Fonte de luz/ comprimento de } \\
\text { onda/ potência/ } \\
\text { Uso de fibra óptica }\end{array}$ & Laser diodo/ $665 \mathrm{~nm} / 100 \mathrm{~mW} / \mathrm{cm}^{2} / \mathrm{Sim}$ \\
\hline Tempo de irradiação & 5 minutos \\
\hline Resultados & $\begin{array}{l}\text { Os canais radiculados do grupo } 1 \text { apresentaram } \\
\text { níveis mais altos de infecção comparados aos } \\
\text { canais do grupo } 2(\mathrm{P}<\text {.0001). }\end{array}$ \\
\hline Conclusões & $\begin{array}{l}\text { A TFD reduz significativamente } \\
\text { bactérias residuais dentro do sistema de canais } \\
\text { radiculados } \\
\text { com o uso de luz de comprimento de onda } \\
\text { apropriado para gerar oxigênio singleto e } \\
\text { radicais livres e também, se reforçada pela } \\
\text { técnica de limpeza químico-mecânica } \\
\text { significa uma promessa substancial como } \\
\text { tratamento coadjuvante. }\end{array}$ \\
\hline \multicolumn{2}{|l|}{ Souza et al. 2010} \\
\hline $\begin{array}{ll}\text { Metodologia } & \text { (Micro- } \\
\text { organismo/ dentes/ solução } \\
\text { irrigadora) }\end{array}$ & $\begin{array}{l}\text { E. faecalis } \\
\text { 70 dentes unirradiculados } \\
\text { Grupo 1: TFD (AM) + } \mathrm{NaOCl} \mathrm{2,5 \%} \\
\text { Grupo 2: TFD (AT) + } \mathrm{NaOCl} \mathrm{2,5 \%} \\
\text { Grupo 3: TFD (AM) + } \mathrm{NaCl} \mathrm{o,85 \%} \\
\text { Grupo 4: TFD (AT) + } \mathrm{NaCl} 0,85 \%\end{array}$ \\
\hline $\begin{array}{l}\text { FS/ concentração/ } \\
\text { tempo de pre-irradiação }\end{array}$ & $\begin{array}{l}\text { Azul de metileno (AM) ou Azul de toluidina } \\
\text { (AT) } / 15 \mu \mathrm{g} / \mathrm{mL} / 2 \text { minutos }\end{array}$ \\
\hline $\begin{array}{l}\text { Fonte de luz/ comprimento de } \\
\text { onda/ potência/ } \\
\text { Uso de fibra óptica }\end{array}$ & Laser diodo/ $660 \mathrm{~nm} / 40 \mathrm{~mW} / \mathrm{Sim}$ \\
\hline Tempo de irradiação & 4 minutos \\
\hline Resultados & $\begin{array}{l}\text { Independentemente do irrigante utilizado } \\
\text { (NaOCl ou NaCl), a instrumentação reduziu } \\
\text { significativamente a contagem bacteriana. } \\
\text { NaOCl foi significativamente mais efetivo do } \\
\text { que o NaCl, e essa diferença persistiu após a } \\
\text { TFD, independentemente do fotossensibilizador } \\
\text { usado (p <0,05), não foram observadas } \\
\text { diferenças significativas entre os dois } \\
\text { fotossensibilizadores (p>0,05). }\end{array}$ \\
\hline Conclusões & $\begin{array}{l}\text { Estes resultados in vitro sugerem que a TFD } \\
\text { com AM ou AT pode não exercer efeito } \\
\text { suplementar significativo nos procedimentos de } \\
\text { instrumentação/ irrigação em relação à } \\
\text { desinfecção intracanal. Poderão ser necessários } \\
\text { mais ajustes no protocolo da TFD para } \\
\text { aumentar a predisposição na eliminação } \\
\text { bacteriana antes do uso clínico ser } \\
\text { recomendado. }\end{array}$ \\
\hline \multicolumn{2}{|l|}{ Garcez et al. 2008} \\
\hline $\begin{array}{ll}\text { Metodologia } & \text { (Micro- } \\
\text { organismo/ dentes/ } & \text { solução } \\
\text { irrigadora) } & \end{array}$ & $\begin{array}{l}20 \text { dentes anteriores com necrose pulpar e lesão } \\
\text { periapical } \\
\text { NaOCl } 2,5 \%+\text { Peróxido de hidrogênio } 3 \%+ \\
\text { EDTA } 17 \%+\text { TFD }\end{array}$ \\
\hline $\begin{array}{l}\text { FS/ concentração/ } \\
\text { tempo de pré-irradiação }\end{array}$ & $\begin{array}{l}\text { Conjugado entre polietilenimina e clorina/ } 2 \\
\text { minutos }\end{array}$ \\
\hline $\begin{array}{l}\text { Fonte de luz/ comprimento de } \\
\text { onda/ potência/ } \\
\text { Uso de fibra óptica }\end{array}$ & Laser diodo/ $660 \mathrm{~nm} / 40 \mathrm{~mW} / \mathrm{cm}^{2} / \mathrm{Sim}$ \\
\hline Tempo de irradiação & 4 minutos \\
\hline Resultados & $\begin{array}{l}\text { A terapia endodôntica deu uma redução média } \\
\text { de } 1,08 \text { log. A combinação com TFD aumentou } \\
\text { significativamente a redução }(1.83 \log , p= \\
\text { 0.00002). }\end{array}$ \\
\hline Conclusões & $\begin{array}{l}\text { Os resultados sugerem que o uso de TFD } \\
\text { coadjuvante ao tratamento endodôntico leva a } \\
\text { uma diminuição aumentada da carga bacteriana } \\
\text { e pode ser uma abordagem apropriada para o } \\
\text { tratamento de infecções bucais. }\end{array}$ \\
\hline
\end{tabular}


Tabela 1 - Continuação. Principais parâmetros da TFD dos estudos científicos selecionados

\begin{tabular}{|c|c|}
\hline \multicolumn{2}{|l|}{ Garcez et al. 2007} \\
\hline $\begin{array}{ll}\text { Metodologia } & \text { (Micro- } \\
\text { organismo/ dentes/ solução } \\
\text { irrigadora) }\end{array}$ & $\begin{array}{l}\text { P. mirabilis e P. aeruginosa } \\
\text { 10 dentes unirradiculados } \\
\text { NaOCl } 2,5 \%+ \\
\text { EDTA } 17 \%+\text { soluçaõ PBS } \\
\text { Grupo controle } \\
\text { Grupo TFD } \\
\text { Grupo TE } \\
\text { Grupo TFD + TE } \\
\end{array}$ \\
\hline $\begin{array}{l}\text { FS/ concentração/ } \\
\text { tempo de pré-irradiação }\end{array}$ & $\begin{array}{l}\text { Conjugado entre polietilenimina e clorina/ } 10 \\
\text { minutos }\end{array}$ \\
\hline $\begin{array}{l}\text { Fonte de luz/ comprimento de } \\
\text { onda/ potência/ } \\
\text { Uso de fibra óptica }\end{array}$ & Laser diodo/ $660 \mathrm{~nm} / 40 \mathrm{~mW} / \mathrm{cm}^{2} / \mathrm{Sim}$ \\
\hline Tempo de irradiação & $1,2,3$ e 4 minutos \\
\hline Resultados & $\begin{array}{l}\text { A terapia endodôntica isoladamente teve } \\
\text { redução bacteriana de } 90 \% \text {, enquanto que a } \\
\text { TFD teve redução bacteriana de } 95 \% \text {. A } \\
\text { combinação teve redução }>98 \% \text {. }\end{array}$ \\
\hline Conclusões & $\begin{array}{l}\text { A utilização da TFD como adjuvante ao } \\
\text { tratamento endodôntico convencional leva a } \\
\text { uma redução estatisticamente significativa da } \\
\text { carga bacteriana. }\end{array}$ \\
\hline \multicolumn{2}{|l|}{ Souros et al. 2006} \\
\hline $\begin{array}{ll}\text { Metodologia } & \text { (Micro- } \\
\text { organismo/ dentes/ } & \text { soluçãao } \\
\text { irrigadora) } & \end{array}$ & $\begin{array}{l}P . \text { gingivalis, } P \text {. intermedia, } \\
\text { F. nucleatum nucleatum, } \\
P . \text { endodontalis } \text { E E. faecalis } \\
\text { 6o dentes unirradiculados } \\
\text { NaOCl } 6 \%+\text { EDTA } 17 \%+\text { TFD }\end{array}$ \\
\hline $\begin{array}{l}\text { FS/ concentração/ } \\
\text { tempo de pré-irradiação }\end{array}$ & Azul de metileno/ $(25 \mu \mathrm{g} / \mathrm{ml}) / 5$ minutos \\
\hline $\begin{array}{l}\text { Fonte de luz/ comprimento de } \\
\text { onda/ potência/ } \\
\text { Uso de fibra óptica }\end{array}$ & Laser diodo / $665 \mathrm{~nm} / 100 \mathrm{~mW} / \mathrm{cm}^{2} / \mathrm{Sim}$ \\
\hline Tempo de irradiação & 5 minutos \\
\hline Resultados & $\begin{array}{l}\text { A TFD com azul de metileno eliminou } \\
\text { totalmente todas as espécies bacterianas, com } \\
\text { exceção de E. faecalis ( } 53 \% \text { de morte). A mesma } \\
\text { concentração de azul de metileno em } \\
\text { combinação com luz vermelha }\left(222 \mathrm{~J} / \mathrm{cm}^{2}\right) \text { foi } \\
\text { capaz de eliminar } 97 \% \text { de } E \text {. faecalis em canais } \\
\text { radiculados utilizando fibra óptica. }\end{array}$ \\
\hline Conclusões & $\begin{array}{l}\text { A TFD pode ser usada como um procedimento } \\
\text { coadjuvante para matar bactérias residuais no } \\
\text { sistema de canais radiculados após o tratamento } \\
\text { endodôntico. }\end{array}$ \\
\hline
\end{tabular}

\section{DISCUSSÃO}

A terapia fotodinâmica objetiva eliminar os micro-organismos que persistem ao preparo químico-mecânico ${ }^{5}$, e baseia-se na interação entre: um fotossensibilizador, uma fonte de luz e o oxigênio, sendo o fotossensibilizador e sua concentração; e a fonte de luz, seu comprimento de onda e potência os fatores que mais podem variar, afetando o resultado final ${ }^{6}$. O seu mecanismo de ação ocorre pela administração de um fotossensibilizador, que é irradiado por uma fonte de luz visível. A absorção da luz excita o fotossensibilizador que, na presença de oxigênio gera substâncias tóxicas para as células bacterianas.

Dentre os quatorze estudos analisados neste trabalho, quatorze afirmam a eficácia da TFD na diminuição dos micro-organismos presentes nos canais radiculares (Tabela 1 ). No entanto, a TFD pode não exercer descontaminação adicional ao preparo químicomecânico, o que pode ser devido à baixa concentração de oxigênio disponível no ambiente dos canais ${ }^{7}$.

Os estudos clínicos constataram a eficácia da TFD na redução de micro- organismos ${ }^{3,4,8}$ e também que a sua associação ao tratamento endodôntico permite neoformação óssea e restauração de estruturas periapicais, podendo ocorrer em menos tempo comparado ao tratamento endodôntico convencional ${ }^{9}$.

O fotossensibilizador mais utilizado nas pesquisas foi 0 azul de metileno, as concentrações variaram de $15^{7,10}$ a $50 \mu \mathrm{g} / \mathrm{ml}^{8}$, com maior frequência de $15^{7,10}$ e $25 \mu \mathrm{g} / \mathrm{ml}^{5,11}$. Ressalta-se que esta concentração do corante afeta o grau de fotodano da TFD e os produtos comerciais devem ser de qualidade e com grau de pureza de $90 \%$, pois o emprego de soluções inapropriadas disponíveis em farmácias para o uso da TFD pode levar à ineficácia da terapia, nisto o azul de metileno apresenta vantagem química, pois os compostos comerciais apresentam a mesma eficácia dos purificados ${ }^{12}$.

O tempo de pré-irradiação é um ponto crítico para o sucesso da TFD, já que se o fotossensibilizador não estiver próximo ao alvo, sua ativação irá resultar na formação de espécies tóxicas em local não desejado ${ }^{13}$. Os tempos pré-irradiação deste estudo foram de 0 segundos $^{14}$ a 10 minutos $^{15}$, sendo mais presente o tempo de 5 minutos ${ }^{1,5,8,9,11,16}$ (Tabela 1), que parece ser o tempo adequado para a sensibilização das bactérias. Isto influenciará diretamente a quantidade e a localização do fotossensibilizador no micro-organismo. Recomenda-se prolongar o tempo de irradiação para a obter-se uma melhor desinfecção. A razão para a eliminação incompleta de bactérias pode ser o curto período de irradiação que levam à baixa concentração de substâncias citotóxicas geradas nos canais e em túbulos dentinários ${ }^{17}$. Recomenda-se prolongar o tempo de irradiação para obter-se uma melhor desinfecção.

O laser diodo é a fonte de luz mais empregada nas metodologias ${ }^{1,3-5,7,8,10-12,15,17,18}$, embora a luz de LED também se mostre como uma fonte de luz alternativa viável ${ }^{14,16}$. Geralmente o laser diodo é comercializado com comprimento de onda de $660 \mathrm{~nm}$, sendo a potência mais visualizada a de $100 \mathrm{~mW}^{8-10,12,16,17}$ e de $40 \mathrm{~mW}^{3,7,15,18}$.

O tempo de irradiação variou desde 30 segundos $^{1,11,14}$ até 15 minutos $^{16}$, com maior recorrência dos tempos de $2^{12,15,18}$ e 5 minutos ${ }^{5,8,16,17}$. Recomenda-se prolongar o tempo de irradiação para obter-se maior desinfecção por aumentar a concentração de substâncias citotóxicas geradas nos canais e túbulos dentinários ${ }^{17}$.

Todos os estudos desta revisão utilizaram fibra óptica ${ }^{1,3-5.7 .8 .10,11,14-18}$; seu uso proporciona 
quantidade adequada de luz, potencializando a eficácia da terapia devido a sua capacidade de distribuir uniformemente a luz em $360^{\circ}$ no sistema de canais radiculares, com o mínimo de perdas, juntamente à compatibilidade com as dimensões dos canais $^{19}$. Assim, a ação da luz estende-se às áreas de difícil acesso, alcançando com facilidade o terço apical, mesmo em molares com raízes curvas, e até mesmo ao biofilme externo ao ápice radicular ${ }^{20}$. As variáveis que envolvem a aplicação da TFD diferem nos estudos, logo, são necessários mais trabalhos, sobretudo in vivo, para que se possa observar resultados clínicos e recomendar um protocolo padronizado para 0 uso desta terapia. No entanto, alguns parâmetros da TFD persistem nas pesquisas, com semelhanças ou variações próximas, apresentando bons resultados na redução das infecções endodônticas.

Sabendo-se dos parâmetros mais recorrentes nas pesquisas, que apresentam-se eficientes na eliminação de micro-organismos, cabe considerá-los como possíveis constituintes de um protocolo: azul de metileno, com concentração entre 15 e $25 \mu \mathrm{g} / \mathrm{ml}$; tempo préirradiação de 5 minutos; laser diodo, com comprimento de onda de $660 \mathrm{~nm}$ e potência de $100 \mathrm{~mW}$; uso de fibra óptica e tempo de irradiação de 5 minutos.

Não há um consenso sobre o protocolo ideal de aplicação da TFD diante às infecções endodônticas, devido à uma gama variada de sugestões envolvendo os diversos fatores como citado neste trabalho. Sendo assim, esta revisão coletou informações importantes que sugerem as melhores opções em relação ao corante e sua concentração, tempo de pré-irradiação, fonte de luz, uso ou não da fibra óptica e tempo de irradiação.

CONCLUSÃO

A literatura apresenta muitos estudos acerca da TFD na Endodontia, demonstrando sua eficácia na desinfecção, e sua atribuição como terapia coadjuvante, que viabiliza a eliminação de micro-organismos persistentes após o preparo químico-mecânico. Assim, o protocolo sugerido suporta sua aplicação na Endodontia, pois reúne os melhores resultados dos artigos analisados nesta revisão.

\section{REFERÊNCIAS}

1. Asnaashari M, Godiny M, Azari-Marhabi S, Tabatabaei FS, Barati M. Comparison of the Antibacterial Effect of $810 \mathrm{~nm}$ Diode Laser and Photodynamic Therapy in Reducing the Microbial Flora of Root Canal in Endodontic
Retreatment in Patients With Periradicular Lesions. J Lasers Med Sci. 2016;7(2):99-104.

2. Komine C, Tsujimoto $Y$. A small amount of singlet oxygen generated via excited methylene blue by photodynamic therapy induces the sterilization of Enterococcus faecalis. J Endod. 2013;39(3):411-4.

3. Garcez AS, Nuñez SC, Hamblin MR, Ribeiro MS. Antimicrobial effects of photodynamic therapy on patients with necrotic pulps and periapical lesion. J Endod. 2008;34(2):138-42.

4. Jurič IB, Plečko V, Pandurić DG, Anić I. The antimicrobial effectiveness of photodynamic therapy used as an addition to the conventional endodontic re-treatment: a clinical study. Photodiagnosis Photodyn Ther. 2014;11(4):549-55.

5. Soukos NS, Chen PS, Morris JT, Ruggiero K, Abernethy AD, Som S, Foschi F, Doucette S, Bammann LL, Fontana CR, Doukas AG, Stashenko PP. Photodynamic therapy for endodontic disinfection. J Endod. 2006;32(10):979-84 .

6. Trindade AC, De Figueiredo JA, Steier L, Weber JB. Photodynamic therapy in endodontics: a literature review. Photomed Laser Surg. 2015;33(3):175-82.

7. Souza LC, Brito PR, de Oliveira JC, Alves FR, Moreira EJ, Sampaio-Filho HR, Rôças IN, Siqueira JF Jr. Photodynamic therapy with two different photosensitizers as a supplement to instrumentation/irrigation procedures in promoting intracanal reduction of Enterococcus faecalis. J Endod. 2010;36(2):292-6.

8. Ng R, Singh F, Papamanou DA, Song X, Patel C, Holewa C, Patel N, Klepac-Ceraj V, Fontana $\mathrm{CR}$, Kent R, Pagonis TC, Stashenko PP, Soukos NS. Endodontic photodynamic therapy ex vivo. J Endod. 2011;37(2):217-22.

9. Firmino RT, Brandt LM, Ribeiro GL, Dos Santos $\mathrm{KS}$, Catão $\mathrm{MH}$, Gomes DQ. Endodontic treatment associated with photodynamic therapy: Case report. Photodiagnosis Photodyn Ther. 2016;15:105-8.

10. de Oliveira BP, Aguiar CM, Câmara AC, de Albuquerque MM, Correia AC, Soares MF. The efficacy of photodynamic therapy and sodium hypochlorite in root canal disinfection by a single-file instrumentation technique. Photodiagnosis Photodyn Ther. 2015;12(3):436-43.

11. Susila AV, Sugumar R, Chandana CS, Subbarao CV. Combined effects of photodynamic therapy and irrigants in disinfection of root canals. J Biophotonics. 2016;9(6):603-9.

12. Savino F, Maccario S, Guidi C, Castagno E, Farinasso D, Cresi F, Silvestro L, Mussa GC. Methemoglobinemia caused by the ingestion of courgette soup given in order to resolve 
constipation in two formula-fed infants. Ann Nutr Metab. 2006;50(4):368-71.

13. Wainwright $\mathrm{M}$, Phoenix DA, Marland J, Wareing DR, Bolton FJ. A study of photobactericidal activity in the phenothiazinium series. FEMS Immunol Med Microbiol. 1997;19(1):75-80.

14. Rios A, He J, Glickman GN, Spears R, Schneiderman ED, Honeyman AL. Evaluation of photodynamic therapy using a light-emitting diode lamp against Enterococcus faecalis in extracted human teeth. $\mathrm{J}$ Endod. 2011;37(6):856-9.

15. Garcez AS, Ribeiro MS, Tegos GP, Núñez SC, Jorge AO, Hamblin MR. Antimicrobial photodynamic therapy combined with conventional endodontic treatment to eliminate root canal biofilm infection. Lasers Surg Med. 2007;39(1):59-66.

16. da Frota MF, Guerreiro-Tanomaru JM, Tanomaru-Filho M, Bagnato VS, Espir CG, Berbert FL. Photodynamic therapy in root canals contaminated with Enterococcus faecalis using curcumin as photosensitizer. Lasers Med Sci. 2015;30(7):1867-72.

17. Xhevdet A, Stubljar D, Kriznar I, Jukic T, Skvarc $M$, Veranic $P$, Ihan $A$. The disinfecting efficacy of root canals with laser photodynamic therapy. J Lasers Med Sci. 2014;5(1):19-26.

18. Soares JA, Santos Soares SMC, Santos César $C A$, de Carvalho MAR, Brito-Júnior $M$, de Sousa GR, Soares BM, de Macêdo Farias L. Monitoring the effectiveness of photodynamic therapy with periodic renewal of the photosensitizer on intracanal Enterococcus faecalis biofilms. Photodiagnosis Photodyn Ther. 2016;13:123-127.

19. Fimple JL, Fontana CR, Foschi F, Ruggiero K, Song X, Pagonis TC, Tanner AC, Kent R, Doukas AG, Stashenko PP, Soukos NS. Photodynamic treatment of endodontic polymicrobial infection in vitro. $\mathrm{J}$ Endod. 2008;34(6):728-34.

20. Dai T, Huang YY, Hamblin MR. Photodynamic therapy for localized infections--state of the art. Photodiagnosis Photodyn Ther. 2009; 6(3-4):170-88.

\section{CONFLITO DE INTERESSES}

Os autores declaram não haver conflitos de interesse

\section{AUTOR PARA CORRESPONDÊNCIA}

\section{Bruna Angélica de Souza Viana}

Rua Senador Rodrigo Lobo, 402, apt. 101, Iriru 89227-557, Joinville - SC, Brasil

brunaang26@gmail.com 